\title{
La muerte y el juez
}

\section{Eduardo Martínez-Rico}

panadero salió de su casa con un cuchillo en la mano izquierda. Era un cuchillo enorme, con el mango de madera oscura y barnizada y la hoja bri-

llante, de unos veinte centímetros de largo y cinco de ancho en la zona en la que el acero entraba en contacto con la madera.

En circunstancias normales no llamaría demasiado la atención. Todo el mundo en el pueblo, incluso las mujeres, llevaba un cuchillo como ése. Pero aquellas circunstancias debían ser distintas: el panadero lo empuñaba en su mano izquierda, cuando lo habitual era que los cuchillos descansasen plácidamente en la funda del cinturón.

Las veces en que aquellos cuchillos se desenfundaron eran tan escasas que se podían contar con los dedos de una mano. La gente los llevaba por tradición, una tradición cuyo origen todos, o casi todos, habían olvidado. Y se usaban tan poco que muchos pensaban que el herrero ya no fabricaba hojas de acero, sino que se limitaba a pegar las empuñaduras que le mandaba el carpintero a la funda que le suministraba el maestro en marroquinería.

Los ojos del panadero delataban que no estaba tranquilo, sino más bien furioso, lo que inquietó al primer vecino que se encontró, el veterinario. 
El veterinario preguntó al panadero:

—iA dónde vas con ese cuchillo?

- Voy a matar al herrero.

—iAl herrero? ¿Por qué? Los cuchillos están mejor en sus vainas. Adornan más y el acero es peligroso por sus reflejos.

- Ya, pero yo tengo motivos para matar al herrero, y por lo tanto para llevar el cuchillo desenvainado.

— ¿Pero qué te hizo? —insistió el veterinario.

- Se acostó con mi mujer.

—iSólo una vez?

—No, muchas — dijo el panadero, cada vez más enfadado.

- ¿Y por qué no matas a tu mujer?

-Porque la quiero mucho... Todavía tengo que pensarlo. Matar al herrero no me importa; lo de mi mujer es más delicado.

- ¿Quién te ha dicho que tu mujer te engaña con el herrero?

- ¿Quién va a ser? Fue ella, claro que fue ella. Es la única que puede estar segura de eso.

El veterinario suspiró, pero lo hizo de tal manera que el panadero no pudo captarlo. Tampoco quería captarlo.

-Veo que tienes tus razones. Te acompaño.

Los dos juntos caminaron por el pueblo. El pueblo era largo y estrecho, muy largo y muy estrecho. A ambos lados de la calle principal, la única calle, sólo había dos líneas de casas. Todas eran de una planta, y también eran largas y estrechas.

El panadero y el veterinario no volvieron a abrir la boca para hablar entre sí. Pero a los pocos metros recorridos se encontraron con el lechero. Éste sólo tenía tres vacas y disponía de todo el día para sentarse a la sombra. No se movía mucho, únicamente para perseguir la sombra. Allí estaba, debajo del alero, cuando les vio pasar.

— ¿A dónde vais vosotros? ¿Y tú qué haces con ese cuchillo?

- Voy a matar al herrero — dijo el panadero.

El veterinario, como ya sabía este diálogo, dejó de prestar atención. Se preguntaba cómo hacía aquel hombre, el lechero, para vivir. Con tres vacas, no podía vender mucha leche, aunque fuera un producto de lujo en el pueblo. Debía de tener otro tipo de negocios. Eso no sería muy raro, porque él tampoco podría vivir de curar a los animales. Sólo había un caballo en el pueblo y tenía una salud de hierro.

El caballo del juez no había estado enfermo nunca y el veterinario lo recordaba desde que era muy niño. Los caballos no eran su especialidad, pero no le parecía normal un caballo tan viejo y con tan buena salud. En el pueblo sólo había gatos, y muy resistentes, aunque no tanto como el caballo del juez. Él siempre quiso ser 
veterinario y nunca le apeteció enterrar a gatos ancianos, con una salud casi tan buena como aquella de la cual gozaba el caballo del juez.

— ¿Quién te lo ha dicho? -inquirió el lechero.

El diálogo había avanzado y el veterinario volvió a prestar atención.

- ¿Y por qué no matas a tu mujer? — preguntó el lechero.

El veterinario no se acordaba de si el lechero estaba casado, si era viudo o soltero. El pueblo no era demasiado grande, ¿cómo no se acordaba de esto? Estuvo a punto de preguntárselo, pero al final no lo hizo.

—Aún no he ordeñado a ninguna vaca — dijo el lechero—, pero da igual. Siempre hay tiempo para ordeñar. Te acompaño.

El sol pegaba fuerte en los tejados de las dos hileras de casas y sobre la arena del camino que recorría el pueblo de un extremo a otro. Los tres hombres estaban acostumbrados al calor y apenas sudaban. El lechero se fijó en los destellos del cuchillo. Los reflejos daban un poco de miedo, pero le gustaban, eran bonitos. Nunca había visto un cuchillo desenvainado. Por supuesto, él llevaba uno en la funda de su cinturón, pero jamás lo había sacado de allí. ¿Para qué?

El panadero, el veterinario y el lechero caminaban en silencio. Parecía como si el cuchillo, en el que rebotaban los rayos del sol, hablara por los tres.

No habían andado mucho cuando se encontraron con el carpintero. Las preguntas y las respuestas fueron las mismas, y el veterinario y el lechero no tenían ningún interés en escucharlas de nuevo.

- Me han encargado unas camas para la casa del juez. Parece que esperan gente. Aún me falta terminar la última, pero podré hacerlo por la tarde. Así que voy con vosotros.

El carpintero se unió a la comitiva. A él siempre le había caído bien el herrero. Le fabricaba unos accesorios estupendos para sus muebles, pero no sabía que era un adúltero. iPobre panadero! Quiere mucho a su mujer y después de llevar tantos años amasando el pan para alimentar a su familia, pensó el carpintero. Había que verlo para creerlo. Y él quería verlo.

El veterinario, el lechero y el carpintero caminaban a la par. El panadero iba un poco más adelantado. Los gatos no llamaban la atención de nadie. Estaban medio dormidos, medio despiertos a las sombras de la calle.

El camino no era demasiado largo. Pasaban por delante de casas a las que un ojo no muy atento hubiera calificado de iguales o casi iguales. Pero no lo eran. Todas tenían su propia personalidad, aunque todas midieran lo mismo de alto y de ancho, y tuvieran igual número de habitaciones. Los jardines tenían las mismas plantas y las mismas flores, pero cada uno ensayaba un orden distinto. No todas las plantas ni todas las flores crecían igual en cada suelo, y había casas con jardines como selvas 
—pequeños oasis en medio del desierto-, mientras que otras tenían que conformarse con unos modestos parterres en mitad del césped.

Allí llovía poco, pero habían conseguido perfeccionar un sistema de aprovechamiento de agua que les permitía estos lujos. Sin embargo, no era raro que una familia pasara sed, bastante sed, por mantener su jardincito de la entrada como una selva. El único que no tenía jardín a la puerta de su casa era el juez, ya que paraba tan poco en el pueblo que no lo necesitaba.

Parecía que los cuatro hombres caminaban por instinto o que el cuchillo los guiaba. La gente salía de sus casas y los miraba. «iA dónde van?», preguntaban algunos. «Va a matar al herrero», respondía a veces el carpintero y, otras, el lechero o el veterinario. En algunas ocasiones, era el panadero mismo quien gritaba: « Voy a matar al herrero».

Iba en cabeza, con su cuchillo al frente y no parecía darse cuenta de la larga cola humana que llevaba detrás. Se le hacía largo el camino. Quería llegar cuanto antes al montículo de arena donde trabajaba el herrero. Aunque tenía prisa, no quería correr. Pensaba en la confesión que le había hecho su mujer esa misma mañana. Se lo había contado todo: cuánto tiempo llevaba con el herrero, cuántas veces se veían a la semana, cuáles eran sus virtudes como amante y la vergüenza que sentía. No esperaba de él otra cosa que lo que estaba haciendo, pero no imploró por su vida. Pero ipor qué se lo había contado? El panadero llegó a la conclusión de que su mujer se había cansado del herrero, de que ya le debían de resultar incómodas las escapadas para encontrarse con su amante. Contárselo al marido era la mejor manera de liquidar su relación con el herrero, aunque eso entrañara un peligro muy grande para ella. La mujer había hecho sus cálculos y debían de ser esperanzadores. Era inteligente y orgullosa, dos cualidades que en el pueblo poseían más las mujeres que los hombres. El panadero contaba con todo esto, pero su modo de proceder no iba a cambiar, aunque su mujer también contaba con eso.

El panadero no miraba atrás ni oía lo que tenía alrededor. Para él no existía la gente que lo acompañaba unos metros a su espalda. Los nuevos que se unían a la comitiva ya no preguntaban al panadero. Ya ni siquiera preguntaban a los que formaban la extraña masa de gente. Simplemente, se unían.

Algunos paseaban cuando vieron al panadero, el cuchillo desenvainado y las personas que le seguían. Otros estaban en sus jardines, contemplando los gatos y el cielo sin nubes. Otros estaban en sus casas, pero oían el ruido de los pasos en la arena y salían a mirar. Al final todos se unían, porque algo diferente tenía que encerrar aquella situación. La curiosidad era una virtud, o un defecto, que no se había aletargado en el pueblo, por mucho que allí nunca sucediera nada interesante. 
Lo primero que les llamaba la atención era el cuchillo en la mano del panadero, los brillos que producía el sol en la hoja, tan desconocidos para ellos. Algo se alteraba en su interior cuando veían el suelo, el cielo, la gente, todo reflejado en el acero del cuchillo. Eran asomos fugaces. Veían el rostro iracundo del panadero, pero la cara y el cuchillo se convertían en la misma cosa, significaban lo mismo. También les sorprendía la gente. En el pueblo nunca se reunían en la calle más de cinco personas, pero el panadero iba acompañado por decenas, centenas... Era el único panadero del pueblo, el que no salía jamás de su casa porque tenía que hacer el pan para todos, día y noche.

Sin embargo, ahora todo el pueblo se le iba uniendo, a él y a su cuchillo. Adelante estaba él, guiado por los brillos de su arma, y en una segunda fila iban el veterinario, el lechero y el carpintero. Detrás de ellos todos los demás.

Cuando, por fin, llegaron, hallaron al herrero detrás de su yunque, con las pinzas en una mano y el martillo en la otra, y el juez, que todos sabían que no paraba mucho por allí.

No hubo disculpas ni insultos. El herrero no se defendió. Cayeron al suelo las pinzas y el martillo. El panadero se abalanzó sobre su pecho y lo apuñaló en el corazón. Después le rajó la garganta de oreja a oreja. En un instante, o quizás en dos instantes, un hombre se convirtió en un cadáver, un cadáver frío.

El asesinado dejó en el yunque una pieza a medio terminar de un metal oscuro, casi negro, azulado. Parecía la argolla de una cadena, pero era imposible que fuera eso en lo que trabajaba. Allí no había cárcel ni nada que se le pareciera.

Todos miraban al herrero zozobrado en un charco de sangre, boquiabierto, y con los brazos y las piernas formando una X. El panadero estaba a un metro de él. Su rostro se mostraba extraño. Había cambiado mucho desde que salió de su casa, hacía unas horas. Ahora no había odio en él, sino una inmensa pena, una pena que arrastraba las lágrimas. Su cuchillo ya no brillaba al sol. La sangre lo teñía por completo. En el primer golpe, se había hundido hasta el fondo en el cuerpo del herrero. El panadero pensaba y sentía que aquello era una vista lamentable.

Las lágrimas empezaron a resbalar por los ojos del panadero. La idea de que aquel rostro no se mostraba como debía corrió como una corriente eléctrica por el grupo.

Se abalanzaron en tromba contra él. Sacaron sus propios cuchillos de sus cinturones. Hombres, mujeres y niños, todos llevaban uno desde que vinieron a este mundo. Lo llevaban pegado a la cintura, día y noche, bien guardado en sus fundas. Era una señal, un símbolo, un adorno quizá, pero incuestionable. Por primera vez en sus vidas desenfundaron su cuchillo y comprobaron que el herrero asesinado, hijo del anterior herrero y nieto del herrero más antiguo del que se tenía noticia directa, había hecho bien su trabajo, porque a cada mango de madera oscura, barnizada 
delicadamente, había hecho corresponder una hoja afilada, larga, precisa y brillante como la que había manchado el panadero. El montículo de arena se llenó de resplandores plateados y dorados, decenas, cientos de resplandores. El acero no era un mito. Existía aunque hasta ahora no les hubiera importado su existencia. Ni uno dejó de hundir su cuchillo en el cuerpo del panadero. Ni el más pequeño de los niños, ni la más tímida de las mujeres, ni el más sensible de los hombres. Nadie dejó de clavar, por lo menos una vez, su cuchillo en los brazos, las piernas, la cabeza, el sexo, la espalda y el pecho del panadero.

Al desenfreno de la sangre sucedió una extraña paz. Como buitres, se replegaron en torno a los dos cadáveres. Las hojas de sus cuchillos, que durante generaciones habían adornado sus vestiduras, estaban cubiertos de sangre. Fue entonces cuando un hombre, no mucho mayor que otros, ni más sabio ni más inteligente, se atrevió a mirar a los ojos de las personas que tenía a su lado.

El primero era el pajarero, la persona que criaba a los pájaros, los cuidaba, los alimentaba y luego los regalaba a sus vecinos a cambio de comida e instrumentos. El segundo cultivaba plantas exóticas y hacía lo mismo que el pajarero. Eran muy amigos y los dos se habían unido a la comitiva al mismo tiempo. El plantero, que así le llamaban, respondió a la mirada del pajarero, y los dos cuchillos se cruzaron en el aire. Sus brazos formaron una nueva X y ambos cuerpos cayeron juntos al suelo.

A nadie le gustaba la cara del otro. Todos veían en todas las caras lágrimas, pena, asco y odio, pero odio hacia ellos mismos. El odio que sentían hacia sí mismos se trasladaba a los demás y nadie juzgaba digno el rostro que tenía delante.

El pueblo entero, arremolinado en el montículo, fue cayendo a la arena. Los brazos se cruzaban y los cuchillos entraban en los corazones. Como una corriente eléctri$\mathrm{ca}$, se fue transmitiendo el odio de vecino a vecino, de hermano a hermano, de padre a hijo y de madre a hija. Entonces todos los cuchillos quedaron clavados y las fundas vacías.

El panadero, irreconocible por los cientos de chorros que manaban - ya menosde las heridas, y el herrero, el único que no había levantado su cuchillo, que aún permanecía en su funda, formaban el centro del círculo.

Y entonces fue cuando apareció él. Venía en su caballo blanco, el caballo cuya longevidad y lozanía nunca comprendió el veterinario. El juez no parecía joven ni tampoco viejo. Su edad era tan indefinible como la de su caballo. Pero tenía el pelo y la barba canosos, aunque muchos pensaban en el pueblo que no tenía el pelo blanco por ser mayor, y que tampoco lo hubiera tenido negro, o castaño, o rubio, de ser joven, porque el juez siempre debió tener el pelo blanco. Lo entendían consustancial al cargo que ostentaba. Tan consustancial y tan blanco como el traje que vestía y que era inmune al polvo de los caminos. 
El juez llegó al montículo en el momento preciso. Sus ojos fueron del panadero al herrero, del herrero al panadero, y de estos dos al círculo de los habitantes del pueblo en el que él significaba la ley. El juez se llevó su mano izquierda a la barba y pareció meditar. Hizo un ademán de bajarse del caballo, pero al final no lo hizo. El magnífico animal había sorteado muy bien los cadáveres, había penetrado con sabiduría en aquel círculo de muerte. Él nunca cambiaría su color, pensó el juez. Al fin y al cabo sólo era un animal, un instrumento.

Allí abajo, a los pies del montículo, aparecieron numerosos gatos. En el pueblo había más gatos que hombres. Eso no era nuevo para él. Pero nunca hasta ahora los había visto tan juntos. A decir verdad, tampoco había visto juntos a todos los habitantes de su pueblo, nunca hasta ahora. El juez se merecía un descanso. Pero antes hizo lo último que él creía que debía hacer. Sacó de su bolsillo un pequeño espejo. No llevaba uno de esos cuchillos que nadie usaba. Siempre le acompañaba aquel pequeño cuadrado; era tan consustancial a su oficio como el caballo o el traje blanco. La diferencia es que él sí usaba su espejo, cada día, aunque no le viera nadie. Sin embargo, hasta hoy no lo había utilizado de aquella forma. El espejo brillaba con destellos muy largos por el montículo: el herrero, el panadero, las hojas de sangre, su pueblo muerto, casi todo su pueblo muerto. Y los gatos, a los pies del montículo, no maullaban, no hacían ruido, se movían con la espalda curva, la cabeza erguida, las colas como látigos, látigos duros, estrictos. Negros.

Cogió el espejo, lo situó debajo de su cara y miró a través de él. Era el juez, es decir, era su propio rostro. Quiso reconocerlo, pero sólo captaba rasgos familiares en lo más superficial que le mostraba el espejo. No le gustaba aquel rostro, no era digno. Fue entonces cuando el juez tomó una decisión importante: nunca más volvería a vestirse de blanco, afeitaría su barba y enseñaría a su caballo a envejecer, a morir. Encontraría en su armario algún traje negro, uno que atrajera el sol en la llanura, todo el calor de la arena y del cielo, un traje que le hiciera cómplice de los gatos.

Tiró el espejo en mitad del círculo. Cayó justo entre el cadáver del herrero y el del panadero, con la cara reflectante hacia arriba. Brilló, brilló demasiado. Si lo hubiera mirado durante un tiempo se habría quedado ciego, pero necesitaba sus ojos. Lo habría roto si hubiera servido de algo. Ahora se llenaría de polvo, como todos aquellos cadáveres.

«iCon qué facilidad se convierte un hombre en tan solo un cadáver inerte!», pensó.

El caballo había comprendido y se alejó del montículo. Sus cascos se ensuciaban con la arena a cada paso, pero cuando se alzaban del suelo ya estaban limpios.

Ella debía de estar en casa, esperándolo. 


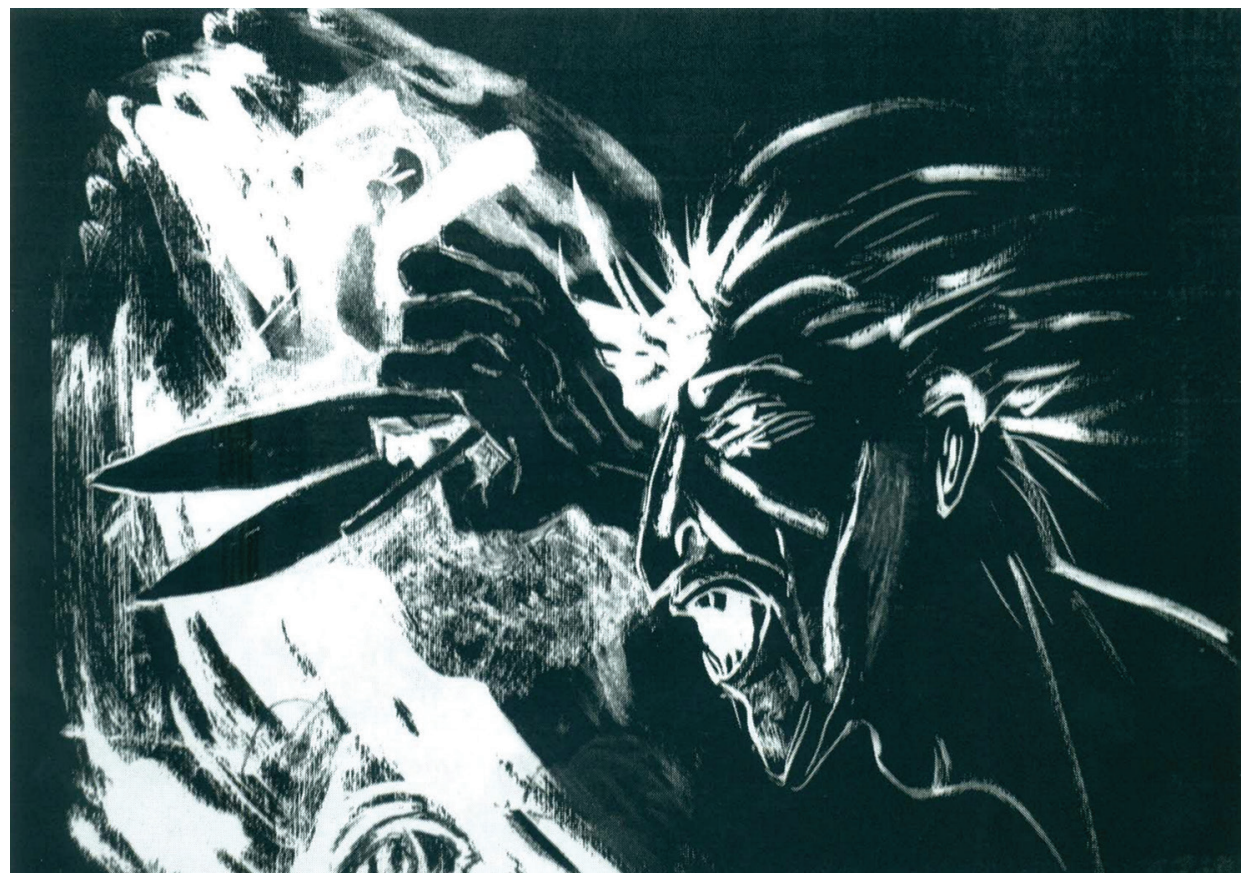

El matadero, Edhasa (2011). Tinta sobre papel: Marcia Schvartz. Prohibida su reproducción en obras derivadas.

Eduardo Martínez Rico. Nació en Madrid (España) en 1976. Se licenció en Filología Hispánica por la Universidad Complutense de Madrid (UCM), España, y se doctoró en Filología por la misma institución. Ha publicado 15 libros de novela, biografía y ensayo. Entre ellos se pueden citar Umbral: vida, obra y pecados. Conversaciones; Pedro J. Tinta en las venas; Cid Campeador; La guerra de las galaxias, el mito renovado; Fernando el Católico. El destino del rey; y Carlos V. El viaje del emperador. Ha sido profesor de Periodismo Cultural en IE University, España, y de Literatura Española en el Colegio de Doctores y Licenciados de la Comunidad de Madrid, España. Ha colaborado en un buen número de publicaciones periodísticas, como Expansión, Época y Qué leer. En la actualidad escribe el blog Cuaderno de campo en la revista digital Zenda. 